\title{
ESTRUTURA, CRIATIVIDADE E TRANSFORMAÇÃO NO LEXICO
}

Izidoro Blikstein

\begin{abstract}
"Claudine: Parfaitement. Il avait cinquante-trois.
Le médecin a dit qu'il était mort de l'embouligue.

César: De l'embouligue?

Claudine: Oui, monsieur, il avait un embouligueL

César: tâtant le nombril): Moi aussi, j’ai un embouligue! (se):

Tout le monde a un embouligue!

Escartefigue (fièrement): Moi, le mien, il est grand comme une pièce de cinq francs!

Claudine (supérieure): Mais ça ne veut pas di`e le nombril! L'embouligue, dans le langage des savants, c'est ane maladie. Le médecin a dit: "C'est une espèce de bouchon qui se met dans les artères. "Et tout d'un coup, cloc! Ça s'éteint comme si on te coupait le gaz!

César (scientifique): Ah! elle veut dire une embolidre!

$M$. Brun (pince-sans-rire): Il y a même des gens qui appellent ça une embolie."

(Marcel Pagnol - César, Dans la salle à manger de Panisse).
\end{abstract}

\section{Introdução}

a) O objetivo do presente artigo é rastrear, na esteira do pensamento linguístico do fim do século XIX até a atualidade, algumas tentativas fecundas de descrição e explicação das configurações formais e semânticas das estruturas léxicas.

b) Em que pese a inegável contribuição do comparatismo histórico e, mais particularmente, dos neogramáticos, para a metodologia da reconstrução lexicológica, é forçoso reconhecer que as palavras eram tratadas pelos comparatistas como "objetos évoluants, mais inac- 
tifs" (1), o que acarretava uma "atomização", e mesmo uma esterilidade, nos estudos lexicológicos: na escrupulosa pesquisa das relações formais entre as palavras aparentadas, as dificuldades semânticas eram mencionadas sem uma particular atenção, desde que as leis fonéticas explicassem a evolução da passarela entre a forma moderna e o seu étimo.

1.3. Alguns lingüistas, como H. Schuchardt, J. Gilliéron, J Jud e A. Meillet, manifestaram-se quanto à necessidade de descrição dos funcionamentos das transformações no plano semântico, o que permitiria uma explicação mais completa da formação das estruturas léxicas. Paralelamente, reflexões e pesquisas mais realistas suscitaram novas perspectivas para a análise dos fatos lingüísticos: nem tudo seria explicado pela genealogia indo-européia, pois a investigação de um falar regional "ao vivo" poderia trazer muitas informações preciosas para uma melhor compreensão da criatividade léxica. Os lingüistas começaram a interessar-se pelo funcionamento da linguagem observado diretamente, libertando-se, de certo modo, de dados "livrescos" sobre fatos que se perdiam no tempo e cuja verificação era impossível: é o caso das renovadoras pesquisas do Padre P Rousselot contidas em Les modifications phonétiques du langage étudiées dans le patois d'une famille de Cellefrouin (1891). Por outro lado, uma nova perspectiva se abria também com reflexões sobre a distribuição das línguas, agora não mais segundo o modelo naturalista da "árvore" schleicheriana, mas sob um ponto de vista muito mais consoante com uma ciência humana que é a linguística: trata-se da $\mathrm{Wel}$ lentheorie, "teoria das ondas", idealizada por J. Schmidt (1872), para quem o fenômeno linguístico se distribui de um modo semelhante ao da irradiação e propagação de ondas concêntricas que "longe de coincidir, se entrecruzam e formam uma grande complexidade de traços dialetais" (2).

1.4. Com a geografia lingüística e a escola das palavras $e$ coisas (Wörter und Sachen), a história das palavras deixou de ser traçada simplesmente por leis fonéticas e passou a ser o resultado do cruzamento e combinação de vários tipos de informação: repartição geográfica das palavras, limites, irradiação, relações com as "coisas" designadas etc. Criatividade e transformação no léxico podem ser explicadas de um modo mais "global" a partir do momento em que a ciência etimológica começa a integrar em seu domínio a história das relações entre significantes e significados, "a do emprego do signo no

(1). - A. Rey - "Le dictionnaire étymologique de W. von Wartburg",

(2). - M. Leroy - As Grandes Correntes da Lingüistica Moderna, pp. 62-3. 
processo social de comunicação e no funcionamento da designação, suscitando a intervenção do conhecimento dos referentes (Sachen)' (3).

\section{História e estrutura no léxico.}

2.1. Um dos resultados metodológicos dessa visão "integralizante" da etimologia foi a necessidade de que os dicionários etimológicos se tornassem históricos, com a introdução da cronologia, localização e descrição dos valores funcionais de cada unidade tratada. Diz W von Wartburg:

"Primitivamente, bastava constatar o ponto de partida e o ponto de chegada da evolução, por exemplo, fazer jour, "dia", remontar ao lat. diurnus; quanto ao problema de saber porque o latim dies teve de ceder seu lugar, como se desenrolou o combate entre essas duas palavras e quais fases sucessivas ele atravessou, a isso tudo se dava uma bem pequena atenção"

Trata-se de uma atitude completamente nova: para o etimologista tradicional, a mudança de sentido era vista como um desenvolvimento espontâneo, a partir de um primeiro sentido, quando a grande maioria dos casos nos mostra que as coisas não são assim tão simples. As variações semânticas envolvem-se numa cadeia complexa de acontecimentos e só poderão ser explicadas, se acompanharmos as transformações do campo de associações em que as palavras se integram de um modo global, em vez de seguir o destino individual de cada palavra. E conhecida a irônica alusão de Gilliéron ao método tradicional utilizado pelos etimologistas, ao comparar suas explicações à seguinte biografia de Balzac: "Balzac, sentado no colo de sua ama, trajava uma roupa azul com listas vermelhas. Escreveu a Comédia Humana" (5). Não, já não basta a genealogia das palavras, mas é necessário determinar a rede de associações formais e semânticas que ligam as palavras entre si num dado sistema linguíistico.

2.2. A palavra viande, "carne comestível", por exemplo, está envolvida numa rede em que também se encontra chère, descendente do termo greco-latino cara, "cabeça", e que significa "bom prato, boa refeição" na expressão faire bonne chère "comer bem" O sentido inicial de viande, "alimento" (do lat. vulg. uॅuenda) restringiu-se para "carne comestível", substituindo a lacuna ocasionada por chair que,

\footnotetext{
(3) - A. Rey, ibidem, p. 87

p. 124 .

(4). - W. von Wartburg - Problèmes et méthodes de la linguistique,

(5). - idem, ibidem, p. 128.
} 
por sua vez, sofreu uma ampliação de sentido, passando de "carne comestível" a "carne" em geral (do corpo humano, dos frutos), adquirindo mesmo uma conotação religiosa, por oposição a "espírito" (cf. Mat. 26,. 1: Spiritus quidem promptus est, caro autem infirma, e fr. la chair est faible). Cabe a pergunta: por que esta ampliação ou generalização de sentido de chair (do lat. carnem)? Aí vai a explicação, baseada nos verbetes viande, chair e chère do Dictionnaire Étymologigue, de Bloch e Wartburg: chair tinha como homônimo chère, cujo significado, "rosto", "cara", foi desaparecendo por volta do século XVII, permanecendo o de "boa comida" em faire bonne chère, "comer bem" ("fazer boa cara, por comer bem") pode-se perceber como a homonímia entre chair e chère certamente provocaria embaraçosas ambigüidades, particularmente durante a quaresma, em que se deve obedecer à abstinência quanto à carne. A partir daí, conforme a nova ótica dos etimologistas, o choque homonímico teria levado o povo a evitar o emprego de chair como "carne comestível", enquanto o sentido de viande se especializava nessa direção semântica. Trata-se, sem dúvida, de uma explicação bem mais ampla do que a resultante da associação binária entre dois termos isolados.

2.3. A noção de família de palavras enriqueceu-se pela explicação das relações entre significados e também por levar-se em consideração a totalidade dos dialetos que forneciam numerosas palavras pertencentes aos subconjuntos funcionais da língua. Muda e amplia-se o conceito de reconstrução que surge agora como uma verdadeira combinatória de numerosos dados recolhidos da história da palavra e de pesquisas dialetais (ilustradas por mapas lingüísticos). $\mathrm{P}$ Guiraud vê essa combinatória como um autêntico "puzzle":

“ de umas trezentas formas reunidas por Wartbu:g e reagrupadas segundo a sua dispersão dialetal, avulta o parentesco de nombril, bourriquet, mounille, ambugnon, lambillot etc., que remontam ao lat. ūmbĭliculus

omblill

Temos três tipos conforme a manutenção ou não das vogais pretônica e postônica, conforme a área dialetal. A partir dessas formas, ocorreu uma série de acidentes... : dissimilação do $l$ em $r$ on $n$; matátese do $l$ (certamente acelerada pela aglutinação do artigo); metátese da vogal inicial (* ombeliculus $>$ oemboliculus) dança de sufixo. Lambill lambillot representa um *emblill com 
dupla metátese do $l$ e da vogal inicial. Mounille é uma aferese de embonill por assimilação do $b$ em contacto com o $m^{\prime \prime}$

E pergunta, ironicamente, Guiraud:

"Mas que leis fonéticas poderiam justificar tais fenômenos?" (6) Trata-se aqui não mais do estabelecimento do étimo (nem sempre observável, aliás, como no caso do indo-europeu) e sim da determinação de liames formais e semânticos dos conjuntos ou famílias léxicas.

2.4. Emerge um princípio básico desse novo tipo de investigação etimológica: as palavras não vivem isoladas dentro do vocabulário e a relação significante/significado deve completar-se com outras relações que ligam as palavras às suas vizinhas. Cada palavra está inserida, então, num campo associativo (7), feito de um entrecruzar de significantes e significados; essa dupla rede associativa, instável, subjetiva, e, no entanto, real estaria subjacente a todas as transformações do léxico. A novidade da nova "escola" etimológica é a introdução do acidental no estabelecimento das famílias ou conjuntos léxicos, pois o jogo de motivações lingüísticas num campo associativo é tão variado e subjetivo que cada palavra é levada a uma situação particular e irredutível, fornecendo leis igualmente particulares e irredutíveis. Decorre, então, um segundo princípio das considerações acima: cada palavra tem a sua história, com seus acidentes e vicissitudes.

2.5. Para a etimologia-história - como quer $\mathrm{K}$. Baldinger, diferenciando-a da etimologia-origem dos comparatistas (8) - é preciso estabelecer a história de cada palavra e, ao longo dessa história, as leis da evolução lingüística - tanto fonéticas quanto morfológicas - são perturbadas por fenômenos parasitários que formam um complexo de relações, único em cada caso. Na comparação de $P$ Guiraud (9), o etimologista deve atuar como o detetive, tentando responder a várias perguntas que envolvem a palavra (como, que, quando, onde, porque, etc.) e tocam fundamentalmente a aspectos de espaço e tempo (visualizados pelos mapas lingüísticos). A cronologia é, pois, decisiva para a filiação etimológica, dirimindo muitos equívocos; basta ler esta bela carta que $\mathbf{P}$ Guiraud não chegou a enviar a Gaston Bachelard:

(6). - P. Guiraud - L'Etymologie, pp. 80-81. t

(7). - Cf. F. de Saussure - Curso de Lingïística Geral, cap. V, 2a parte (Relações sintagmáticas e associativas); cf. Ch. Bally, "L'arbitraice du signe", in Le Français Moderne, VIII, 1940.

(8) - K. Baldinger, "L'Etymologie hier et aujourd'hui", p. 239.

(9). - P. Guiraud, op. cit., pp. 37-8. 
"Meu caro Mestre, estou lendo La Poétique de la Rêverie: sobre o feminino e masculino, há coisas de estremecer a Lingüística inteira mas que são muito de meu agrado.

Mas é de outra coisa que gostaria de falar-lhe. À p. 9, relevo a seguinte fase: "A Psicologia tem mais a perder do que a ganhar, por formar suas noções básicas inspirada em derivações etimológicas. Assim é que a Etimologia amortece as diferenças mais nítidas que separam rêve "sonho" de rêverie "devaneio", o que o embaraça; mas, na verdade, a Etimo!ogia concorda com sua intuição.

Rêverie data do século XII e rêve do XVII, constituindo duas palavras dife entes.

Eis a situação. Existe um verbo antigo resver (com formas raver) de origem bem enigmática - a etimologia proposta por Wartburg não é, segundo penso, inteiramente probatória —, mas seu sentido e c.onologia, de qualquer modo, estão bem estabelecidos: a palavra significa "vagabundar" com o sentido se. cundário (p'óprio desse semantısmo) de "delirar" (sair do sillon "sulco"), "divagar" etc.; tal verbo tem como substantivo resverie com derivados resvasser, resveur, resvasseur, resvasserie...

No fim do século XVI, resver adquire seu sentido metafórico moderno e substitui songer, formando-se, ao mesmo tempo um novo pós-verbal,rêve.

Mo fo'ogia semântica e cro o'ogicamente, rêve e reverie remontam a duas fo'mas diferentes de étimo, o que deve alegrálo, espero. É claro, porém, que rêve e rêverie se contaminaram posteriormente; o sentido inicial evidencia-se, no entanto, ainda em expressões como "vous rêvez, mon ami" (você está sonhando, meu amigo) e, certamente, nas rêveries, "devaneios" de um promeneur solitaire. Rêveur, "sonhador", é bem ambíguo, mas o filósofo rêveur que é, meu caro Mestre, nos vem diretamente da alta Idade Média. Curioso é que, enquanto, rêver substitui Songer, este último assume o antigo sentido de rêver. Mas isto é outra história...

\section{A seguir, explica Guiraud:}

"Esta era minha carta; mas - como acontece - ficou alguns dias em minha escrivaninha - e, numa manhã, morria Bachelard e calava-se a fonte mais generosa no aido racionalismo da erítica universitária francesa. Era a mais bela figura desse Álbum imaginário dos Mestres que não tive. Eu o amava.

O leitor deve compreender o sentimento que me leva a enviar hoje a carta que nunca seguiu. E espero que me descul- 
pe o desvio para demonstrar-lhe a importância da cronologia" (10).

Também eu devo desculpar-me por este desvio, mas a transcrição da carta de Guiraud ilustra, ao mesmo tempo a atualidade da prática etimológica e seu envolvimento no contexto das Ciências $\mathrm{Hu}-$ manas, enquanto, por outro lado, sugere a necessidade de os lingüistas não ficarem presos e "bitolados" em seus esquemas e quadros mentais - pretensiosamente exatos e quantificáveis -, mas abrir-se para uma finalidade mais ampla, de cunho humanístico.

\section{Problemas e contribuições da etimologia-história}

3.1 A constatação das "vicissitudes" ou "acidentes" do campo associativo da palavra - que trazia a vantagem de provocar a abettura da Etimologia para o imprevisível - acarretou um corolário bem peculiar: a necessidade de controlar esses "acidentes", numa perspectiva quase antropomórfica. As palavras são atacadas de "doenças" como desgaste fonético, contaminação de forma e sentido, colisões homonímicas, conflitos e, nesse sentido, os títulos das obras de J Gilliéron são bem sintomáticos: Phatologie et thérapeutique verbales (1921), Thaumaturgie Linguistique (1923) etc. Impressiona a Gilliéron, por exemplo, que apis "abelha" tenha chegado a es, por desgaste fonético, mas tenha sido eliminada ou substituída, de um modo geral, por derivados morfológicos (avette, abeille, apette etc.) ou derivados semânticos (mouche à miel, mouchette etc.), sendo que a forma provençal abeille se generalizou finalmente. Tais acidentes são encarados por Gilliéron como próprios da "patologia" da comunicação linguística; essa perspectiva vai arrastar a Etimologia a uma metalinguagem perigosa, por ser marcadamente "antropomórfica" e externa à Lingüística .

3.2. A observação das "doenças" fonéticas e homonímicas sugere uma visão sincrônica do léxico, ficando evidente que a criação verbal pode ser determinada dentro do campo associativo de uma palavra ou pelas relações dos vários campos associativos no seio da estrutura lingüística. Mas estrutura é ainda uma idéia implícita em Gilliéron, Wartburg e outros e as consequiências das observações feitas por esses estudiosos são ainda puramente empíricas e externas à Lingüística (11). Na prática, entretanto, devemos reconhecer que a nova escola introduz a análise sincrônica do léxico, ao observar, não propriamente a história isolada da palavra, mas a história de suas relações

(10). — idem, ibidem, pp. 39-40. z

(11). - idem, ibidem, p. 76. 
formais e semânticas. A Etimologia começa a tomar uma direção estrutural, combinando história e sistema, como assinalou Baldinger: “ . a história de coxa é, ao mesmo tempo, a história de femur, fimus $e^{*}$ hanka. Desde que haja história da palavra, há evolução do sistema" (12). Outra contribuição do método léxico-histórico foi a introdução de preocupações semânticas; com efeito, o campo associativo da palavra apresenta-se como um sistema de dupla "entrada": de um lado, registra-se a forma léxica, sua evolução, acidentes e colisões com concorrentes, de outro lado, anotam-se os acidentes semânticos, geradores de novas relações de sentido. Abrem-se assim as primeiras perspectivas para os estudos semasiológico-onomasiológicos do vocabulário; a nova orientação já se ensaia, aliás, nas preocupações de alguns estudiosos no tocante à criação léxica e semântica, como se pode depreender de alguns títulos de capítulos, cuja semelhança nos chama a atenção:

1 - Comment naissent les mots, in La vie des mots, de A. Darmesteter ( 1 a edição: 1887);

2 - Comment se créent les mots, in La vie du langage, de W D. Whitney (trad. franc. de 1875);

3 - Comment les mots changent de sens, de A. Meillet, (in Année sociologique de 1905-6, inserido mais tarde em Linguistique historique et linguistique générale, 1958);

4 - Comment les mots changent de sens e Comment les notions changent de nom in Le Langage, de $\mathrm{J}$. Vendryes (terminanado em 1914, mas editado apenas em 1920)

4 Criatividade e transformação, segundo Darmesteter, Whitney, Vendryes e Meillet

4.1 O fato de Darmesteter, Whitney, Vendryes e Meillet revelarem uma preocupação semelhante quanto à formação e organização do vocabulário não significa uma identidade de critérios e métodos de análise. Ao contrário, cada um vai procurar, à sua maneira, conforme seu conceito de linguagem, uma explicação para as mudanças semânticas e formais do vocabulário.

4.2. Começarei por Arsène Darmesteter, cuja obra, La vie des mots, já contém, embrionariamente, uma tentativa de semântica "estrutural" Com efeito, neste "livrinho" (como o chama o próprio nutor) tão representativo da linguística do fim do século XIX e tão zriticado por sua lógica metafórica impregnada de antropomorfismo ("família", "língua-mãe", "vida", "juventude", "velhice" das palavras), en-

(12) - K. Baldinger, ibidem, p. 243. 
saia-se o estabelecimento de uma verdadeira análise componencial do significado. E o que se pode observar, quando Darmesteter esboça uma "teoria" para a explicação das modificações mais complexas de sentido das palavras; duas seriam as causas: o rayonnement "irradiação" e o enchaînement, "encadeamento" (13). ção":

4.2.1 Assim Darmesteter explica o rayonnement, "irradia-

"Seja $\mathrm{N}$ o nome de um objeto $A$, seja a uma qualidade qualquer considerada em $A$, o nome $\mathrm{N}$ passará a outros objetos $B, C, D, E, F . G$, etc., graças à mesma qualidade $a$ que cada um dos objetos possuirá em meio a outras. O seguinte esquema mostrará o fato:

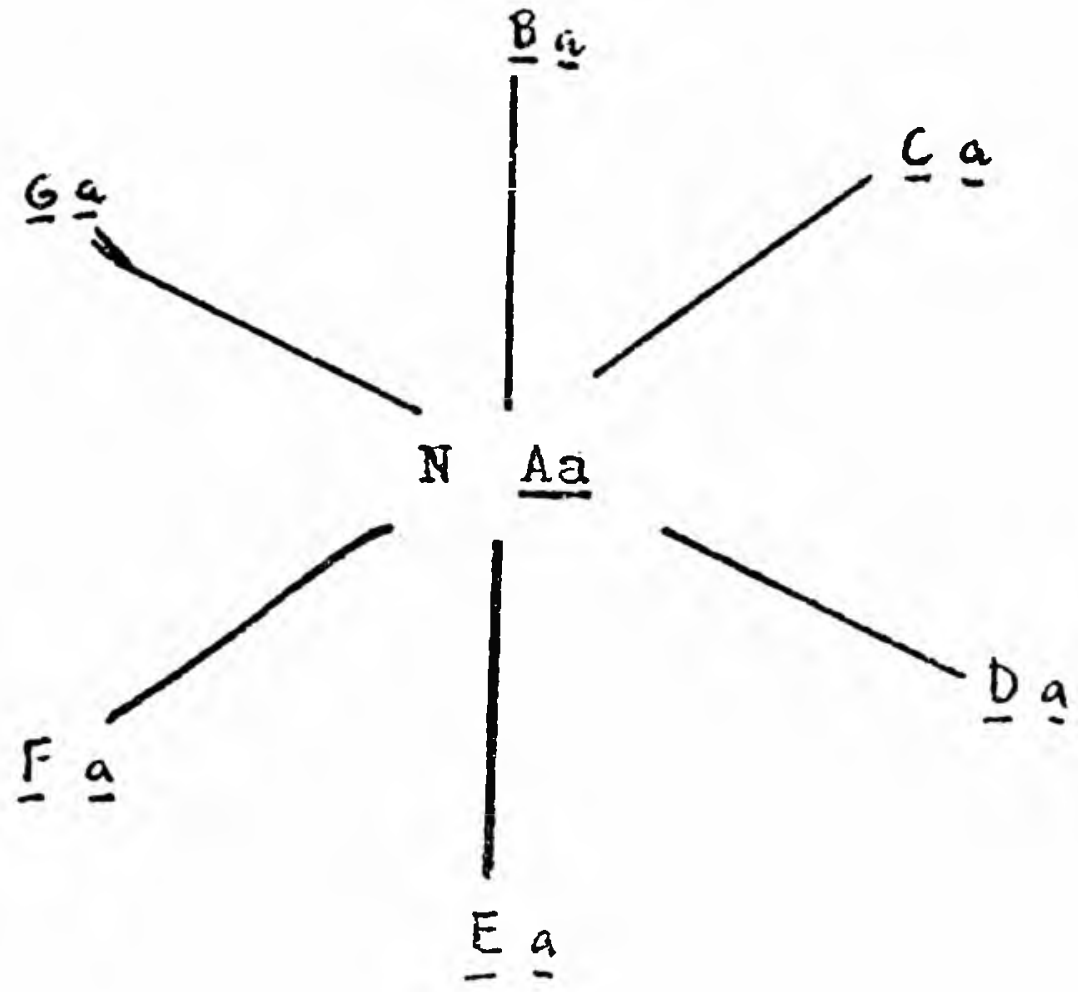

(13) - A. Darmesteter - La vie des mots, pp. 74-5.

(14) - idem, ibidem, pp. 74. 
4.2.2. Quanto a enchainement, "encadeamento", comenta c autor:

"Às vezes, a lingua considera, num objeto de nome N, duas três, etc. qualidades diferentes, propiciando a passagem desse nome a divessas séries de objetos que têm em comum com $A$, um, uma qualidade $a$, outro, uma qualidade $b$, um terceiro, uma qualidade $c$, e assim por diante. Esquema:

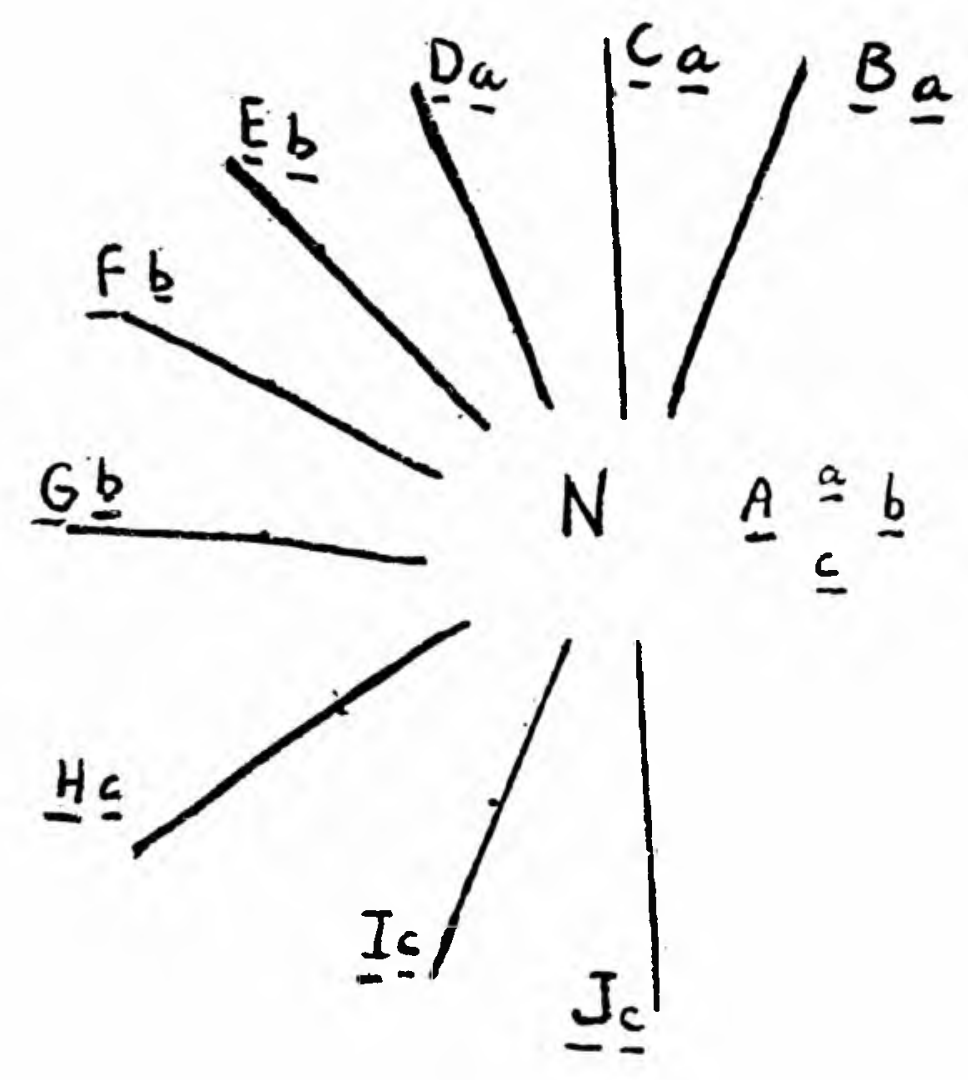

4.2.3. Vejamos uma aplicação destes esquemas à palavra tête, "cabeça":

"Por exemplo, a cabeşa considerada como a parte superior e extrema do corpo dará os empregos figurados: cabeça de linha, cabeça de ponte etc.; considerada em sua forma física, dará cabeça de alfinete, cabeça de martelo etc.; considerada como sede do pensamento, dará ter cabeça, cabeça fraca etc." (16)

Esta análise semântica, apoiada na teoria da "irradiação", coloca Darmesteter numa posição singular e avançada para seu tempo. Com efeito, nem Bréal chegou a vislumbrar tais estruturas de signifi-

(15). — idem, ibidem, p. 75 .

(16). - idem, ibidem, loc. cit. 
cação: sua irradiation nada tem a ver com o já referido rayonnement (17), a restriction e o élargissement (18) não chegam a explicar o mecanismo interno das metáforas que, por sua vez, são tratadas em seus aspectos mais externos propriamente.

Já Darmesteter vislumbra a possibilidade de uma explicação mais interna, mias lingüística, mais. "estrutural": o nome cabeça designa uma parte do corpo com duas qualidades - superioridade e extremidade - que se estendem ou se irradiam a determinados objetos; pois bem, não deixa de ser relevante o fato de Greimas, na redução sêmica de tête, chegar a um resultado semelhante, ao extrair o núcleo sêmico comum: extremidade + superatividade (19)! Com esta aproximação entre Darmesteter e Greimas, não tenho, evidentemente, o intuito de estabelecer uma filiação direta entre ambos e nem insinuar - o que seria pior! - falta de originalidade na elaborada análise de Greimas. Não, quero apenas mostrar como, na linguística nascente, do século XIX, alguns pensadores mais atilados já acalentavam o projeto de examinar as estruturas "profundas" da linguagem para explicar, depois, as mutações de "superfície" Mas é claro que há uma diferença considerável de pontos de vista e concepções entre os referidos lingüistas: com efeito, enquanto, por um lado, os esquemas de Darmesteter mostram uma relação direta entre o nome $(\mathrm{N})$ e o objeto (A), portanto, entre signo e referente, a abordagem de Greimas é, eminentemente, semiológica, isto é, a estrutura de significação é articulada pela própria língua e não pela realidade a que essa língua se refere. Assim, o que Darmesteter analisa como qualidades do objeto, $a, b, c$, ou $d$, são, na verdade, os traços sêmicos do significado, conforme Greimas; em outras palavras, superatividade ou extremidade não são qualidades do objeto e sim do significado ou referência.

4.3 A abordagem de Whitney é bem diferente. Para ele, a criação léxica estaria condicionada a uma lei fundamental que regula a comunicação: a lei da comodidade; o suporte teórico dessa explicação encontra-se na concepção convencionalista de Whitney:

"Quando a faculdade humana de dar nomes às coisas desperta, ela toma simplesmente, e sem seguir out:a lei senão a da comodidade, os materiais que se apresentam, sem indagar-se muito curiosamente acerca de sua proveniência. $\mathrm{Na}$ realidade, o objetivo a que visa é encontrar um signo que possa estar, doravante, estreitamente ligado a um conceito, e ser empregado, ao mesmo tempo, para o pensamento íntimo bem como para o pensimento

(17). - M. Bréal - Essai de sémantique, cap. III, parte I.

(18). - idem, ibidem, caps. X e XI, parte II.

(19). - A. J Greimas - Sémantique Structurale, p. 48. 
comunicado. Se:ia inútil procurar outra coisa, quando o liame pelo qual todo o vocabulário se !iga ao espírito é, em cada indivíduo, um liame puramente convencional"

.3.1 Tal concepção implica uma perspectiva totalmente sincrônica do léxico, sem lugar para a investigação etimológica de caráter diacrônico:

" A criança apreende as palavras como lhe são dadas e as associa às mesmas idéias que as outras pessoas.

. As questões etimológicas nada significam para ela..

.O fato é que tais questões não interessam tampouco aos adultos, e o próprio etimologista não se atrapalha de modo algum com elas, na prática. " (21)

As lembranças etimológicas constituiram até obstáculos à comunicação:

"Já observamos, mais de uma vez, como os homens estão dispostos a esquecer as origens de suas palavras e a suprimir, como obstáculos inúteis, as lembranças etimológicas, a fim de concentrar toda a força da palavra no rovo objeto a que está ligada"

4.3.2. Whitney chega, então, a divisar, nesta disposição humana a esquecer os "obstáculos etimológicos", uma das tendências fundamentais da faculdade de criar palavras:

"Eis aí uma das tendências fundamentais e mais importantes da faculdade de fazer palavras: ela contribui, de modo essencial, para tornar a linguagem mais prática"

E, além de sugerir a inutilidade de explicações etimológicas, acaba por resumi-las todas numa única lei, a da comodidade, distinta $\mathrm{e}$ acima da necessidade:

(20). - W. D. Whitney - La vie du langage, p. 117 A obra de Whitney está a merecer uma cuidadosa leitura. Saussure reconhece a sua importância, cintando-o na Introdução do Curso. Nosso mestre, o Prof. Isaac Nicolau Salum, chamou-nos a atenção para o fato de que Whitney chega mesmo a empregar o termo arbitrário, referindo-se a signo: “... signes qui n'ont pas... un lien nécessaire avec les conceptions qu'ils expriment, mais sont .. arbitraires et conventionnels.

(Whitney, ibidem, p. 20).

(21). - idem, ibidem, p. 117

(22) - idem, ibidem, loc. cit.

(23). - idem, ibidem, loc. cit. 
"Ao contráiio, há razões para tudo; mas o uso atual da palavra não depende delas; elas nem sempre são descobertas e, quando o são, percebe-se que estão fundamentadas na comodidade e não na necessidade"

4.3.3. Todas estas considerações estão em função do conceito de Whitney acerca da linguagem:

"Não se trata de uma potência, nem de uma faculdade; não é sequer o exercício imediato do pensamento; trata-se de um produto mediato desse pensamento, isto é, um instrumento"

Para Whitney, a linguagem seria, então, apenas um érgon "produto" e um instrumento de comunicação; não estamos longe da corrente "mecanicista" (de inspiração behaviorista), encabeçada por L. Bloomfield, para quem a comunicação lingüística não é mais do que a resposta (r) a nossos estímulos (E), que provocará um estímulo linguístico (e) no ouvinte, conduzindo-o à uma resposta comportamental (R), correspondente ao estímulo original (E). (26)

4.3.4. A perspectiva sincrônica e convencionalista de Whitney - bastante salutar para a descrição lingüística estruturalista - apresenta o inconveniente de reduzir a linguagem a um simples mecanismo de "condicionamentos", sem considerar um aspecto mais profundo, o da enérgeia, isto é, a criatividade lingüística. O vocabulário não é apenas um produto mas sobretudo uma estrutura dinâmica e não é totalmente correto que a criança, como quer Whitney, adquira as palavras "como lhe são dadas"; daí as ressalvas feitas a essa corrente lingüística "mecanicista" por N.Chomsky:

"A criança pode apreender uma grande parte de seu vocabulário e perceber a estrutura da frase ao assistir à televisão, ler, ouvir os adultos etc. Mesmo uma criança pequena, que ainda não adquiriu um mínimo de repertório, de modo a formar novas frases, pode imitar uma palavra bastante bem, ou pelo menos tentá-lo, sem esperar que seus pais lho ensinem. É óbvio também que, num estágio posterior, a criança estará apta para construir e compreender frases praticamente novas, e que são, ao mesmo tempo, aceitáveis em sua linguagem"

(24). - idem, ibidem, p. 119.

(25). - idem, ibidem, p. 229.

(26). - L. Bloomfield - Language, pp. 24-27

(27) - N. Chomsky - "Verbal Behaviour, by B. F. Skinner", reviewd by $\mathrm{N}$. Chomsky, in Language, 35, 1, 1959, p. 42 . 
4.3.5. Do funcionamento sincrônico da comunicação lingüística, Whitney extrai, como foi visto, uma das grandes tendências da linguagem: os homens esquecem obstáculos etimológicos a fim de concentrar toda a força da palavra em torno de seu uso atual, guiados pela comodidade (e não pela necessidade). Não fosse a confusão entre comodidade e necessidade ou a desnecessária distinção entre ambas, Whitney estaria bem perto da verdade científica da aludida tendência. Martinet esclareceria, mais tarde, o que ele denominou a economia lingüistica:

"A evolução lingüística pode ser concebida como regida pela antinomia permanente entre as necessidades comunicativas do homem e a tendência a reduir ao mínimo a sua atividade mental e psíquica" (28)

Whitney roçou de perto essa tendência fundamental da comunicação lingüística que é transmitir o máximo de informação com um mínimo de elementos formais, mas sua explicação foi ainda inadequada: não se trata de comodidade ou necessidade e sim de dialética constante entre eficácia de comunicação e economia de esforço na atividade comunicativa. E nem seria muito exato invocar a "lei do mínimo esforço" (alunos universitários, até mesmo em nível de pós-graduação, recebem com ironia a expressão "mínimo esforço", como se o gênero humano fosse indolente mesmo ao comunicar-se!): economia aqui implica sobretudo eficácia na transmissão da informação e a publicidade está, a qualquer momento, aplicando a lei da economia, com suas fórmulas telegráficas, quase icônicas, em que um máximo de informação deve ser transmitido com um mínimo de significantes:

OS FINS JUSTIFICAM AS MEIAS

ENTRE DE SOLA NA ESCOLA

A NOBREZA ADERIU À MORTADELA

90\% DE VOCE E ROUPA, VALORIZE ESTE ESPAÇO

4.3.6. A economia lingüística, que, conforme nos mostra Martinet, funciona nos eixos paradigmático e sintagmático da língua (29), é a força motriz das alterações formais e semânticas. É assim que E. Benveniste ultrapassa a Semântica clássica, procurando explicar em profundidade o mecanismo das mudanças de sentido, no célebre e antológico artigo Problèmes sémantiques de la reconstruction:

(28) - A. Martinet - Elements de linguistique générale, p. 176.

(29). - Idem, ibidem, p. 177. 
"Na reconstrução de um processo semântico devem entiar também os fatores que provocam o nascimento de uma nova "espécie" de sentido" (30)

E o principal fator para Benveniste reside na perda da especificidade de uma palavra por desgaste provocado por seu uso intenso e variado, o que leva a um enfraquecimento de sentido; há, conseqüentemente, uma perda de informação e a economia lingüística é posta $\mathrm{cm}$ jogo: surge, então, um substituto do termo desgastado para renovar a informação primeira. Não é, portanto, muito exata a radical visão sincrônica de Whitney no tocante à criação verbal: o falante não utiliza um signo mecanicamente, abstraindo-se do lastro diacrônico que o envolve; ao contrário, segundo Benveniste, o aparecimento de um novo sentido é provocado por um "jogo" diacrônico-sincrônico nos eixos sintagmáticos e paradigmáticos. O variado emprego de um signo em diversas seqüências sintagmáticas acarreta diluição do sentido ou da informação, havendo, então, uma substituição paradigmática: entra um novo signo com o sentido ou informação primitiva. Assim é que a explicação, segundo a qual, o sentido atual do fr tête, "cabeça", provém de uma metáfora jocosa (lat. testa, "jarra, moringa", > tête "cabeça" cf. Dictionnaire Etymologique de Bloch-Wartburg), parece ficar na superfície dos fatos. Explica Benveniste:

"O problema começa com o nome da "cabeça" em latim clássico. Verifica-se que caput não significa somente "cabeça", mas também "pessoa", e ainda "capital (financeiro)". "capital (de uma província)"

São apresentados os sintagmas em que se encontra caput:

“ $\quad$ entra em ligações como caput amnis, "fonte, embocadura ou cabeceira do rio", caput coniurationis, "chefe da conjuração", caput cenae, "peça principal de uma refeição", caput libri, "capítulo de livio", caput est ut, "é essencial que" etc. (32)

A variação de sequiências sintagmáticas implicará o desgaste de sentido ou informação:

"O número e a extensão dessas variantes enfraqueciam a especifidade de caput "cabeça", o que conduzia a duas soluções possiveis. Ou o termo seria redeterminado como *caput corporis

(30). - E. Benveniste - Problèmes de linguistique générale, p. 295.

(31). - Idem, ibidem, pp. 295.

(32). - Idem, ibidem, p. 295. 
que teria sido, ele próprio, ambíguo e que, de qualquer modo, a língua rejeitou, ou seria substituído por outro. Foi o que aconteceu em latim mesmo, por meio de testa, que designava qualquer concha dura e foi inicialmente aplicada ao que ainda chamamos de "caixa craniana" O sentido de "crânio" aparece claramente em latim tardio (Antoninus Placentinus: uidi testam de homine, "vi um crânio (ou caveira) de homem") e já servia para denominar a "cabeça": testa: caput vel vas fictile (C.G.L., V. 526-39), de onde, em francês antigo, teste, "crânio" E provável que, como termo de anatomia, testa já fosse usado pelos médicos romanos bem antes de os textos o mencionarem" (33)

E Benveniste conclui, observando que os nomes de partes do corpo formam um campo sempre suscetível de uma renovação de informação e deixando claro que as transformações ocorridas neste campo léxico devem-se a mecanismos profundos da criatividade lingüística e não aos jogos e brincadeiras da linguagem:

"Não há pois, nesse processo, nem brincadeira e, na verdade, nem uma singularidade especial de nos chamar a atenção. (o processo) oferece simplesmente um aspecto particular da renovação que atingiu a maioria dos nomes de partes do corpo" (34)

O signo lingüístico encontra-se, destarte, numa complexa rede diacrônico-sincrônica e os "souvenirs étymologiques" não constituem propriamente obstáculos mas componentes fundamentais na dialética informação/economia. A criação verbal supõe sempre algo anterior e é neste sentido que a linguagem não é um simples érgon "produto" mas uma energeia "atividade", ou melhor ainda (como quer Coseriu), uma possibilidade de ir além do que já foi realizado (35).

4.4. J Vendryes foi além de Whitney no que respeita às interpretações acerca das transformações do léxico. Mas não chegou à profundidade de Benveniste: ficou no meio do caminho, pois enxergou o aspecto do desgaste semântico (usure sémantique) mas permaneceu na superfície dos fatos, invocando sempre causas externas ao mecanismo lingüístico:

(33). - Idem, ibidem, pp. 295-6.

(34). - Idem, ibidem, p. 296.

(35). - E. Coseriu — anotações do I Seminário de Linguística, promovido pela Association Internacionale de Linguistique Appliquée, (A.I.L.A.), em Besançon, França, 1965. 
"Não é menos grave o desgaste semântico. O emprego frequiente desgasta as palavras tanto em seu sentido como em sua fo:ma; e, sobretudo se se trata de palavras expressivas, o valor expressivo se atenua rapidamente com o uso. A palavra torna-se gasta e apagada. Quando se trata, por exemplo, de exprimir as emoçōes da alma, vemos as palavras mais fortes cair pouco a pouco no descrédito e, finalmente, sair de uso, pois já não são mais expressivas"

441 Conforme as observações de Benveniste transcritas anteriormente, a explicação de Vendryes pode ser criticada em vários aspectos: não é bem usure ("desgaste") de significado que sofrem as palavras de frequiente emprego e sim perda de especificidade, o que, aliás, pode ocorrer em qualquer área do vocabulário. Por outro lado, Vendryes parece circunscrever o fenômeno da usure à área de palavras que qualifica como expressivas, por exemplo, as que exprimem as emoções da alma; ora, na verdade, qualquer palavra pode adquirir a função expressiva e referir-se a qualquer significado: não é pertinente o fato de uma palavra referir-se a emoções da alma, bem como não é muito adequado falar em "palavras mais fortes", "descrédito" etc., pois, trata-se de uma metalinguagem externa à Linguística. Dentro dessa perspectiva, Vendryes analisa a palavra tête:

"A palavra tête, "cabeça", é um teimo de gíria com relação a caput; e se tête, por sua vez, viesse a ser destronada por fiole ou bobine (37), isso representaria um novo êxito em favor da gíria" (38)

$\mathrm{E}$ as seguintes considerações justificam bem a crítica de Benveniste às interpretações clássicas da Semântica, impregnadas de "psicologia":

"Denominar a cabeça com o nome pote é um fato tão natural que pode ser observado em outras línguas, principalmente em germânico, em que o alemão Kopf é aparentado ao latim cupa $e$ ao escandinavo kollr, tirado de kolla, "pote"

Ora, a argúcia de Benveniste nos mostrou que a relação entre cabeça e pote não é tão natural assim e pode ser explicada por um minucioso exame das ocorrências da palavra dentro do mecanismo paradigmático sintagmático da língua.

(36) - J. Vendryes - Le Langage, p. 240.

(37). - Alguns exemplos equivalentes em português: cuca, moringa, etc.

(38). - J. Vendryes, ibidem, p. 241.

(39) - Idem, ibidem, loc. cit. 
4.4.2. Outra causa externa citada por Vendryes para a explicação da usure semântica é a social:

"Mesmo nos exemplos precedentes, a psicologia não explica tudo. O desgaste que sof:em as palavras sempre se deve um pouco à ação do meio social em que são empregadas. Convém, então, examinar sob o aspecto social a questão do renovamento dos vocabulários. A causa social aparece nitidamente nas transformações das palavras por razões de decência" (40)

A decência, o tabu a atividade social ou profissional seriam geradores de metáforas ou metonímias, por meio das quais as palavras mudam de sentido. Mas a ênfase dada às causas psicológico-sociais afastam Vendryes da análise interna das mudanças semânticas; o eminente Lingüista acalentará, a partir daí, a tentadora idéia de estudar as condições psicológicas e sociais dos povos:

"Tanto quanto acerca da psicologia, as transformações de sentido informam também a respeito das condições sociais dos povos" (41)

Seguem-se inferências totalmente externas à lingüística e bastante discutíveis:

"Deste modo, o vocabulário inglês revelaria, sem dúvida, um maior respeito do que o nosso [isto é, o francês] no que se refere às coisas religiosas e às pessoas dedicadas a Deus. Entre o alemão e o francês, denunciar-se-iam, do mesmo modo, certas diferenças. Ambos de bom grado aplicam nomes de animais a pessoas; mas; muitas vezes, impregnamos esse uso de um sentimento de ironia, desprezo ou insulto. Já o alemão, mais sentimental, acrescenta-lhe, de preferência, um matiz de afeição"

São muito contestáveis tais considerações: na verdade, qualquer falante, de qualquer língua, pode ser mais ou menos respeitoso, irônico, sentimental ou afetuoso; o léxico de uma língua pode ser manejado em todas as direções, pois, constitui um sistema bastante "aberto" Aprioristicamente, o léxico nada informa quanto ao sentimentalismo ou irreverência de um povo.

(40). - Idem, ibidem, p. 243.

(41) - Idem, ibidem, p. 233.

(42). - Idem, ibidem, p. 232. 
4.4.3. E por esse caminho, entretanto, que Vendryes reivindicará a criação de uma semântica geral ,nitidamente influenciado por Bréal:

"Pode-se prever a constituição de uma semântica geral que, centralizando as informações tiradas de cada língua sobre mudanças de sentido, permitirá reunir estas sob alguns princípios, não do ponto de vista simplesmente lógico, como tem sido feito até agora, mas do ponto de vista psicológico. Para tal, seria preciso partir não de palavras, mas das idéias que representam"

Apesar da validez do projeto - estabelecimento de uma semântica geral - a direção de Vendryes é exatamente oposta à dos semanticistas modernos (Greimas, Pottier, Coseriu, Guiraud etc.): com efeito, pleitea-se hoje uma semântica que parta justamente dos signos que, por sua vez, como quer Hjelmslev, envolvem tanto o plano da expressão como o do conteúdo. Assim, uma semântica psicológica, baseada em conteúdos (e não em palavras!), como pretendia Vendryes, nada teria de propriamente linguístico. A Lingüística contemporânea está justamente em busca de sua própria lógica e chega a ser incorreta a crítica de Vendryes ao já tão criticado Darmesteter, quanto a leis gerais que explicariam as mudanças de sentido:

"Essas leis nunca se encontram nas próp-ias palavras. O defeito do livro de Darmesteter foi conduzir à crença numa lógica interna que regularia as transformações semânticas das palavras" (44)

E até irônico observar que Darmesteter estava, talvez, mais perto das grandes tendências da semântica moderna, ao tentar, justamente, o estabelecimento de uma lógica interna das transformações pela decomposição dos significados (que inadequadamente chama de "objets") em qualidades.

4.4.4. Quero lembrar que as ressalvas aqui feitas não tiram absolutamente o mérito dos citados capítulos do livro de Vendryes que viu, com muito acerto, a importância das famílias de palavras para a conservação ou evolução de sentido:

"Esses exemplos mostram a que ações estão sujeitas as palavras por parte de outras palavias da mesma família lingüística". (45)

(43). - Idem, ibidem, p. 228.

(44). - Idem, ibidem, p. 218.

(45). - Idem, ibidem, p. 220. 
E, quase em contradição com a idéia da "semântica psicológica" e externa à linguística, o autor vislumbra a existência de mecanismos lingüísticos internos:

"Produz-se no cérebro um trabalho inconsciente que fixa as palavras em certos sentidos e as piepara, de um modo geral, para os diversos empregos a que se destinam" (46)

Esta noção do "trabalho inconsciente" é retomada mais adiante, quando Vendryes invoca a teoria da harmonia imitativa de M. Grammont para explicar a criação da palavra kodak:

"A palavra kodak tem imagem, uma imagem auditiva: acreditamos ouvir o disparador do mecanismo que abre e fecha o aparelho. O criador da palavra teria percebido esse valor e quis fazer harmonia imitativa? E possível, mas não necessário. Há sempre um acordo inconsciente que se estabelece entre os sons e as coisas."

“. . Ao batizar, com um nome forjado de ponto em branco, um objeto qualquer, não podemos deixar de estar inconscientemente guiados por correspondências subjetivas entre os sons e os objetos. Uma palavra como kołak está conforme, aliás, com as regras da linguagem onomatopaica: as consoantes têm a articulação justa, e as vogais, o timbre imposto pelas próprias leis de M. Grammont. Está tão bem formada que nos perguntamos se poderia ser de outro modo" (47)

Apesar de marcadas ainda por uma psicologia externa ao fato lingüístico em si, tais considerações desembocam numa conclusão surpreendemente avançada para a época:

"A faculdade de criar palavras novas não passa, provavelmente, de uma ilusão. Esta conclusão nos faz voltar ao grande princípio da evolução lingüística, segundo o qual as línguas procedem por transfosmações (grifo meu) de elementos existentes e não por críiação"

A idéia de transformação já estava presente, de fato, na Fonética e Morfologia comparativas, mas não no léxico, difícil de ser regulado por leis gerais. Vendryes acaba chegando a duas idéias nucleares da etimologia estrutural de P Guiraud, como veremos adiante: o simbo-

(46). - Idem, ibidem, loc. cit.

(47). - Idem, ibidem, pp. 254-55.

(48). - Idem, ibidem, p. 255. 
lismo fonético de matrizes formais e a transformação destas matrizes, gerando novas formas.

4.5. Já a análise de Meillet é de cunho eminentemente sociológico. Reconhecendo os limites das classificações lógicas e lamentando que o Essai de Sémantique, de M. Bréal, não chegasse a apresentar a pesquisa de um sistema "complet et fermé" de mudanças de sentido (49), o Autor assinala alguns fatores sociais responsáveis por mudanças lingüísticas:

4.5.1 a - o caráter descontínuo na transmissão da linguagem: cada nova geração recria a linguagem que herdou de seus pais, modificando-a (50);

b - desagregação de famílias de palavras: as palavras afastam-se muito da raiz primitiva, deixam de apoiar-se umas nas outras e expõem-se à ação de "diversas influências que tendem a modificar o sentido" Meillet exemplifica o fato com a família ligada à raiz *tek-/*teg- "cobrir", em que o sentido de algumas palavras especializouse, afastando-se de sentido primitivo: tegmen, "o que serve para cobrir, roupa" e tegere "cobrir" estão bem ligados à raiz, mas tectum "teto": tegula "telha" e toga manto, toga" apresentam um distanciamento semântico da raiz, provocado pelo isolamento dessas palavras (51);

c - mudança nas coisas designadas pelas palavras: pai e mãe, continuação normal de pater e mater, já não exp:imem as mesmas noções por não estar associadas às mesmas representações que as palavras latinas ou indo-européias (52);

d - "ação da divisão dos homens em classes distintas no sentido das palavras" (53), causa já assinalada por Vendryes e, antes, por Bréal;

e - constituição heterogênea dos grupos sociais também intervém nas alterações do vocabulá:io (54).

Entre todos os citados fatores, Meillet elege a pressão dos grupos sociais dentro de uma comunidade em que se fala determinada língua como o princípio essencial da mudança de sentido, observando que: t. I, p. 234 .

(49). - A. Meillet - Linguistique historique et linguistique générale,

(50). - Idem, ibidem, p. 235.

(51) - Idem, ibidem, p. 237.

(52) - Idem, ibidem, p. 241.

(53) - Idem, ibidem, p. 244.

(54) - Idem, ibidem, p. 248. 
se é verdade que uma transformação de sentido não possa produzir-se sem ter sido provocada por uma causa definida - e este é o postulado necessário a qualquer teoria sólida em semântica -, o princípio aqui invocado é o único conhecido e imaginável cuja intervenção seja suficientemente poderosa para explicar a maio:ia dos fatos observados; e, por outro lado, a hipótese é verificável no lugar em que as circunstâncias permitem acompanhar de perto os fatos" (55)

Meillet exemplifica o fato com o verbo chasser "expulsar": proveniente do lat. vulg. captiare (ligado a capere "tomar, prender"), chasser adquiriu, no grupo dos caçadores o sentido de "empurrar, impelir adiante para capturar", perdendo depois a precisão técnica e passando simplesmente ao sentido de "empurrar, impelir, expulsar" (56).

Queixando-se do silêncio dos dicionários etimológicos quanto às causas das mudanças de sentido, Meillet propõe um princípio de método para a investigação etimológico- semântica:

a - convém examinar primeiramente a forma da palav:a e seu grau de isolamento na língua: uma palavra isolada comportase diferentemente de uma inserida num grupo; é p:eciso inteirarse também da possível influência da forma e do papel, na frase, das associações fônicas que desperta;

b - acompanhar a história das coisas significadas e sua influência na palavra e conexões com o resto do vocabulário;

c - é preciso sobretudo, assinalar por quais grupos sociais a palavra foi transmitida, passando de uma língua particular a outra (57).

4.5.3. Aqui, o mérito de Meillet está em reconhecer a dificuldade de traçar uma metodologia uniforme de investigação, variadas que são as causas das mudanças de sentido. Algumas considerações suas já podem ser hoje criticadas, como, por exemplo, a tese da transmissão descontínua da linguagem: as modificações que uma nova geração pode introduzir no sistema lingüístico que herdou ficam, em geral, no nível das "estruturas superficiais" como resultados de transformações dos modelos profundos da estrutura linguística (como propõem Chomsky, Coseriu e outros); parece, então, que, apesar de registrar a distinção humboldtiana érgon / enérgeia (58), Meillet não

(55) - Idem, ibidem, p. 257.

(56) - Idem, ibidem, p. 259.

(57) - Idem, ibidem, p. 267

(58). - A. Meillet - Introduction à l'étude comparative des langues indo-européennes, p. 460 . 
a explorou suficientemente, admitindo - incorretamente, a meu ver que uma geração receba de outra anterior um sistema lingüístico como apenas produto: ao contrário, quando uma criança aprende uma língua, o que ela aprendeu, na verdade, foi a criação ou transfiormação (enérgeia) de modelos.

4.5.4. Apesar de tais ressalvas, é claro que fica um valioso e positivo saldo da análise de algumas idéias "lexicológicas" de Meillet: a importância que atribuiu ao papel do referente, do contexto e da situação social nas análises semânticas coloca-o na ordem do dia, agora, com as modernas perspectivas da sociolingüística.

4.6. O traço dominante de todos esses autores e "escolas" do fim do século XIX e início do século XX é a ênfase no fator psicológico-social para a interpretação de problemas inacessíveis ao comparatismo histórico. Mas, com razão, adverte $\mathrm{P}$ Guiraud:

"Mas sobre a natureza lingüística (e não simplesmente lógica) da metáfora, da derivação ou de qualquer outro modo de criação léxica, sabemos pouca coisa; a natureza dessas relações não tcmı sido reconhecida, sistematicamente; e a conjectura repousa, no final das contas, unicamente nos dados imediatos da evidência externa" (59)

A evidência interna, linguística propriamente, da criação léxica levará P Guiraud a ensaiar o estabelecimento de uma etimologia (ou lexicologia) "estrutural", a até mesmo "transformacional"

\section{Em direção a uma Etimologia "estrutural" ou "transformacional"}

5.1 A coexistência de história e sistema, sugerida pela escola de Wartburg e Baldinger, desemboca numa preocupação dominante da Lexicologia contemporânea: reduzir a massa do léxico a um sistema estruturado (60). Esta idéia já se esboça nas constelações formais e semânticas de Saussure (geradas pelas relações sintagmáticas e associativas de um signo), nos campos associativos de Bally (61), nas esferas ou campos conceituais de Weisberger, Trier ou Matoré (62), acabando por traduzir-se numa verdadeira declaração de princípio em defesa de uma organização estrutural do léxico: o léxico não é um

(59). - P Guiraud - L'Etymologie, pp. 86-7

(60). - P. Guiraud - "Distribution et transfo:mation de la notion de "coup"' in Langue Française, 4, dezembro, 1969, pp. 67-74.

(61) - St. Ullmann - Semântica - pp. 476-7

(62). - Apud A. Rey - La lexicologie, p. 130 e W von Wartburg ibidem pp. 170-73. 
amontoado de palavras, un tas de mots (63), a bag of words (64), a piling up of lexations (65) ou un répertoire de mots (66). Bem representativo dessa nova orientação lexicológica é Pour une sémantique structurale, resposta de Louis Hjelmslev à pergunta Dans quelle mesure les significations des mots peuvent-elles être considerées comme formant une structure? formulada no VIII Congresso Internacional de Lingüística (67). Reconhecendo a dificuldade do estabelecimento de uma semântica estrutural, pois o próprio léxico apresenta-se "caprichoso e justo o contrário de estrutura", o eminente lingüista propõe a decomposição da substância semântica de um signo por meio da função comutação:

"Dois membros de uma paradigma pertencentes ao plano da expressão (ou significante) são chamados comutáveis (ou invariantes), se a substituição de um desses membros por outro acarretar uma substituição análoga no plano do conteúdo (ou significado); inversamente, dois membros de um paradigma do conteúdo são comutáveis, se a substituição de um por outro acarretar uma substituição análoga na expressão"

Decorre daí que, onde não há comutação, ocorre substituição e os membros do paradigma serão simplesmente variantes. O campo do parentesco ilustrará como comutação e substituição variam de uma língua a outra; Hjelmslev parte de quatro grandezas semânticas (irmão e irmã mais velhos, o caçula e a caçula) analisadas diferentemente em húngaro, francês e malaio:

\begin{tabular}{|c|c|c|c|}
\hline & húngaro & francês & malaio \\
\hline "irmão mais velho" & bátya & \multirow[b]{2}{*}{ frère } & \multirow{4}{*}{ sudarà } \\
\hline "o caçula" & $\ddot{o c c s}$ & & \\
\hline "irmã mais velha" & néne & \multirow{2}{*}{ soeur } & \\
\hline "a caçula" & húg & & \\
\hline
\end{tabular}

Desta comparação podem ser extraídos as componentes invariantes e mínimas dos signos, ponto de partida para a decomposição sê-

(63). - Idem, ibidem .

(64). - G. Mounin - Clefs pour la sémantique, pp. 49-50.

(65). - Z. Harris - "Distributional structures", in Word, v954, no 2 e 3, pp. 146-162 e apud G. Mounin - Los problemas teóricos de la traducción, p. 41 .

(66). - A. Martinet, ibidem, p. 10.

(67). - L. Hjelmslev — Essais lingustiques, pp. 105-121.

(69) - Idem, ibidem, p. 113. 
mica de Greimas e Pottier; esta análise semântica componencial re. partiria o significado de égua em "cavalo" + "fêmea"

5.2. Outra perspectiva para investigar a organização estrutural do vocabulário é a contextual e quem melhor formalizou seu princípio básico foi Benveniste no decisivo Problèmes sémantiques de la reconstruction:

"O princípio único de que nos utilizaremos nas considerações que se seguem, tomando-o como aceito, é o de que o "sentido" de uma forma linguíística se define pela totalidade de seus empregos, po: sua distribuição e pelos tipos de ligações que eles resultam" (70)

E bem lembrar que tal princípio já se encontra esboçado no já comentado artigo de Meillet - Comment les mots changent de sens -em. que o sentido de uma palavra define-se por uma média entre os empregos linguísticos, de um lado, e os indivíduos e grupos de uma mesma sociedade, de outro lado. Na linha de Benveniste, modernamente, está o filósofo Wittgenstein para quem "o significado de uma palavra é seu uso na língua" (Philosophical Investigations, p. 20) (71)

5.3. Guiado por esse princípio, $P$ Guiraud parte em busca de evidências lingüisticas internas que expliquem a criação léxica. Examinando minuciosamente a ocorrência e emprego de um grande número de signos, o Autor procura determinar-lhes um denominador semântico comum denominado protossemantismo:

"Assim, por trás de centenas de palavras, encontramos uma série de sinônimos, baseada ruma imagem arcaica comum, e que denominarei de bom grado o protossemantismo. E é de se compreender toda a difefrença entre uma relação externa e completamente isolada que associa fortuitamente dois objetos e duas roções e esse semantismo profundamente integrado no sistema da língua, o qual precipita e atualiza a metáfora"

A esse protossemantismo corresponderia um protomorfismo, constitu indo ambos um campo morfo-semântico de dupla entrada: de um lado os paradigmas formais correspondentes a determinadas categorias se-

(70). - E. Benveniste, ibidem, p. 290.

(71). - L. Wittgenstein, Philosophical Investigations, p. 20 e apud Ullmann, ibidem, p. 132 .

(72) - P Guiraud - L'Etymologie, p. 101. 
mânticas, de outro, os paradigmas semânticos correspondentes a categorias formais. Assim, para explicar a criação léxica, o etimologista deveria detectar as estruturas elementares morfo-semânticas, ou matrizes, responsáveis por novas formaçōes:

“ essas estruturas elementares, esses paradigmas, são verdadeiras matrizes, isto é, fôrmas em que vertemos as palavias, mas, além disso, com a idéia de um certo dinamismo, na medida em que tais estruturas, apenas por sua existência, tendem a precipitar novas formações e a engendrar novas palavras"

Sublinhei dinamismo, pois é esta a idéia nodular de Guiraud:

"E a palavra "dinamismo" não é uma figura e sim, um verdadeiro "campo de fo:ças" conjuntas e "compostas" que está na origem da criação da palavra - e, de qualquer modo, de seus empregos e valo:es. O que denominamos campo morfossemântico é essencialmente a reconstrução desse feixe de forças; ou melhor, de um sistema de motivações complexas que se compõem e se equilibram. Em tal campo, as palavras não estão isoladas. O problema tradicional da cor:espondência entre forma e sentido é substituído pelo da convergência de um conjunto de sentidos e de conjunto de formas"

5.3.1 O dinamismo do campo morfo-semântico foi bem demonstrado por Guiraud na análise da Distribution et transformation de la notion de "coup" (golpe) (75). O Autor levanta um inventário de cerca de 500 palavras construídas a partir de um elemento $\mathrm{T} \mathrm{K}$. (com alternâncias vocálicas ou consonânticas: $T I K / T A K / T O K$, TOK / TOCH / TAK, TRIK / TRAK / TROK); há também outro étimo, C. K., com iguais alternâncias, e ainda $\mathbf{P}$ K., M. K., T P etc. Para Guiraud, todos esses étimos e alternâncias constituem "onnmatopéias cinéticas nas quais os movimentos dos órgãos da fala mimam os do membro ou instrumento portador do golpe, sendo que a vogal indica se o mesmo é chato, penetrante ou contundente" (76) A partir daí, vai sendo detectado o semantismo profundo e suas transformações, com os diversos tipos de golpe e, para cada um deles, a ação, o agente ou instrumento e o resultado:

(73). - Idem, ibidem, p. 106.

(74). - Idem, ibidem, p. 119.

(75) - Guiraud - "Distribution et transformation. ", loc. cit.

(76) - Idem, ibidem, p. 68. 


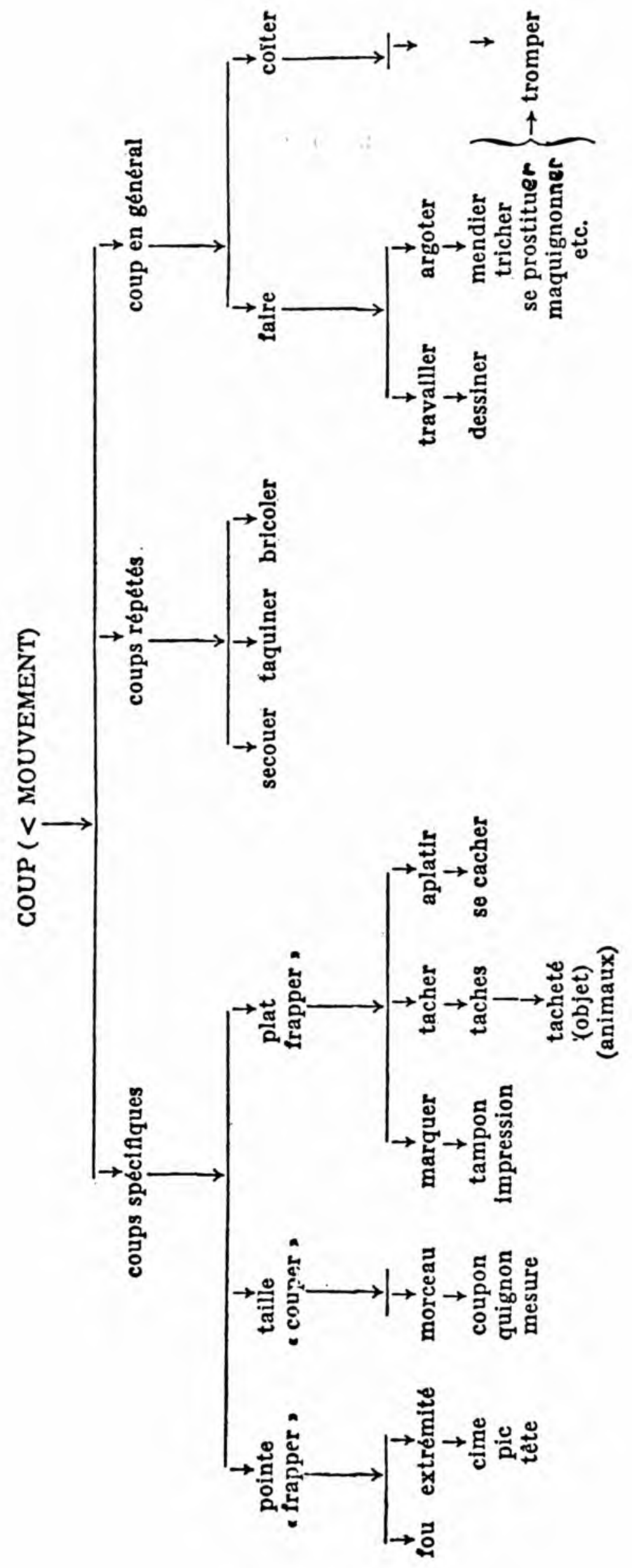


E interessante notar certos cruzamentos de semantismos nesta "árvore" transformacional que esclarecem muitos problemas etimológico-semânticos, jamais explicáveis pela Etimologia clássica; assim de "couper" "bater" derivam nomes que indicam o paciente, o homem que sofreu o golpe; mas esse semantismo não é direto, pois, passa por um sentido especial de couper, toquer, piquer "fraper la cloche" e cruza-se com o semantismo coupe "tête" (cabeça). O toqué, toc, piqué, marteau ou timbré é o homem que levou um golpe na cabeça e ficou meio "doido" (77)

Observa, então, Guiraud:

"Assim, pouco a pouco, afastamo-nos da estrutura profunda, mas a cadeia dessas transformações é perfeitamente simples e coerente. Toda análise etimológica tradicional deve ser retomada em função destas regras; não se poderá constatar outra coisa senão o parentesco morfossemântico de termos separados por sua origem histórica" (78)

5.3.2. $P$ Guiraud procura assim uma relação necessária entre expressão e conteúdo que constituíria, em última análise, a reconciliação entre estrutura e história, sincronia e diacronia, arbitrariedade e motivação do signo lingüístico. A Etimologia estrutural de Guiraıı, baseada num dinamismo transformacional, permite entender a reinterpretação da distinção érgon / enérgeia feita por Coseriu. Com efeiło, este lingüista, indo além mesmo de Chomsky, divisou, entre érgon e enérgeia, a dúvauıs "força" ou, mais precisamente, "potencialidade":
“ uma atividade pode ser considerada:

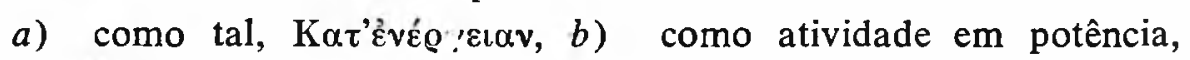

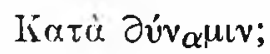

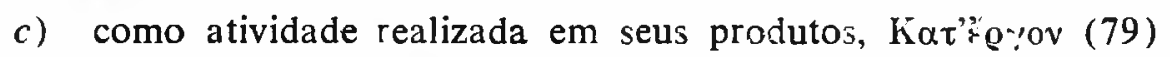

5.3.3. E no nível da dýnamis que se situam as matrizes lexicogênicas de Guiraud. A Etimologia estrutural seria a afirmação "da existência necessária de longíquos protomorfismos e protossemantismos, estrutura dupla e acrônica sem a qual só se poderia compreender o aspecto externo e superficial das coisas da linguagem." (80).

(77). - Idem, ibidem, pp. 69-70.

(78). - Idem, ibidem, p. 74.

(79) - E. Coseriu - Teoría del lenguage $Y$ lingüística general, p. 286

(80) - J P. Colin - "À propos de Structure étymologiques du lexique français", de P Guiraud", in Langue Française, 4, dezembro, 1969, pp. 120-123 


\section{BIBLIOGRAFIA}

1. - Baldinger, K. - "L'Etymologie hier et aujourd'hui" in Cahiers de l'Association internationale des études françaises, Paris, maio, 1959, $\mathrm{n}^{\circ} 11$.

2. - Benveniste, E. - Problèmes de linguistique générale, Paris, Gallimard, 1966 (vol. I).

3. - Bloch, O. e W. von Wartburg - Dictionnaire Etymologique de la langue française, Paris, P.U.F., 1964.

4. - Bloomfield, L. - Language - Nova Iorque, Holt, Rinehart and Winston, 1962.

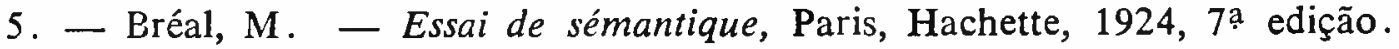

6. - Chomsky, N. - Revitw (resenha): B.F. Skinner - Verbal Behaviour, in Language, vol. 35, $\mathrm{n}^{\mathbf{9}}$ 1, jan.-março, 1959.

7. - Colin, J.-P - "Ã propos de Structures étymologiques du lexique français, de $\mathrm{P}$ Guiraud, in Laitgue Française, $\mathrm{n}^{\circ}$ 10, maio, 1971, Paris, Larousse.

8. - Coseriu, E. - Teoria del lenguage y lingüística general - Madrid, Gredos, 1969 .

9. - Darmesteter, A. - La vie des mots - Paris, Delagrave, 1918.

10. - Greimas, A.J - Sémantique structurale - Paris, Larousse, 1966.

11. - Guiraud, P. - L'Etymologie - Paris, P.U.F., 1964.

- Structures étymologiques du lexique français, Paris, Larousse, 1967.

- "Distribution et transformation de la notion de coup", in Langue Française, $\mathrm{n}^{\text {\% }}$ 10, maio, 1971, Paris, Larousse.

12. - Hjelmslev, L. - Essais linguistiques - Paris,Minuit, 1971.

13. - Leroy, M. - As Grandes Correntes da Lingüistica Moderna - São Paulo, Cultrix, 1971.

14. - Martinet, A. - Elements de linguistique générale, Paris, A. Colin, 1967.

15. - Mato:é, G. - La méthode en lexicologie - Nouvelle éciition refondue, Paris, Didier, 1973.

16. - Meillet, A. - Introduction à l'étude comparative des langues générale - t. I, Lib. H. Champion, 1958; t. II, Klincksieck, 1952, Paris.

17 - Mounin, P - Clefs pour la sémantique - Paris, Seghers, 1972.

- Los Problemas Teóricos de la Traducción - Madrid, Gredos, 1971.

- La Lingustique Du XXème Siècle - S.U.P., P.U.F., Paris, 1973. 
18. - Rey, A. - La Lexicologie - Paris, Klincksieck, 1970.

- "Le dictionnaire étymologique de $W$ von Wartbu"g, structures d'une description diachronique du lexique", in Langue Française, $\mathrm{n}^{\mathrm{P}}$ 10, maio, 1971, Paris, Larousse.

19. - Ullmann, it. - Semântica — Lisboa, Gulbenkian, 1967

20 - Vendryes, J. - Le Langage - Paris, Albin Michel, 1968.

21. - Wartburg, W von - Problèmes et méthodes de la linguistique Paris, P.U.F., 1963.

22. - Whitney, W.D. - La vie du langage, Paris, Lib. Germer Baillière, Paris, 1875 . 